\title{
OS DESAFIOS DA ESCOLA PÚBLICA NA RELAÇÃO COM AS POLÍTICAS SOCIAIS ${ }^{1}$
}

\section{CHALLENGES OF PUBLIC SCHOOL IN RELATION WITH SOCIAL POLICIES}

\author{
ALGEBAILE, Eveline ${ }^{2}$
}

\begin{abstract}
RESUMO
O artigo analisa as relações contemporâneas da escola pública com políticas de assistência social, no Brasil, identificando suas características, contradições e pontos de tensão. Tendo como ponto de partida a discussão das relações entre educação escolar e saúde no contexto histórico de emergência e consolidação do campo da saúde escolar, no final do século XIX e início do século XX, o artigo busca apresentar, a partir desse exemplo, aspectos relevantes das relações entre políticas para a análise da educação escolar, no Brasil. Dentre outros aspectos, destaca o intenso uso estratégico da infraestrutura e da ação escolar para a realização da assistência, em face da intensificação do ingresso de diferentes frações da classe trabalhadora na escola; as alterações da gestão e da ação escolar, diante da disseminação de programas focais realizados via escola e dos consequentes impasses relacionados à multi e intersetorialidade, aí implicados; e os desafios relacionados à formação e à atuação profissional nesse contexto de ampliação da esfera escolar.
\end{abstract}

Palavras-CHAVe: Escolarização; Políticas sociais; Educação brasileira; Trabalho escolar; Expansão escolar.

\section{ABSTRACT}

The article analyzes contemporary relations between public school and social assistance policies in Brazil, identifying their characteristics, contradictions and points of tension. Taking as a starting point the discussion of the relationship between school education and health in the historical context of the emergence and consolidation of school health in the late 19th and early 20th centuries, the article attempts to introduce relevant aspects of the relations among policies for the analysis of school education in Brazil. The article highlights, among others: the intense strategic use of school infrastructure and action for the implementation of assistance, vis-à-vis the growing entry of different fractions of the working class into school; the changes of management and school action, regarding the dissemination of focal

\footnotetext{
${ }^{1}$ Este artigo foi originalmente elaborado como base de nossa participação no III Fórum Serviço Social na Educação, realizado pelo Grupo de Estudos e Pesquisa sobre o Serviço Social na Educação GEPESSE, de 27 a 29 de agosto de 2013, na UNESP, Campus de Franca, SP. A presente versão incorpora aprofundamentos provocados pelas ricas interlocuções propiciadas pelo evento, das quais destaco as inestimáveis trocas com os professores Eliana Bolorino Canteiro Martins (UNESP) e Ney Luiz Teixeira de Almeida (UERJ).

${ }^{2}$ Professora Associada da Faculdade de Formação de Professores (FFP) da Universidade do Estado do Rio de Janeiro (UERJ). Professora do Programa de Pós-Graduação em Políticas Públicas e Educação (PPFH) e Procientista da UERJ.
} 
DOI: $10.12957 / \mathrm{e}-m o s a i c o s .2017 .30296$

programs conducted via the school and of the consequent dilemmas related to the implication of multi and intersectoral approaches; and the challenges related to formation and professional action in this context of expansion of the school's scope.

KeYwORDS: Schooling; Social policy; Brazilian education; School work; School expansion.

\section{INTRODUÇÃO}

Ao falarmos em escola pública, a definição que nos vem mais imediatamente ao pensamento é a de uma instituição especializada que tem por função formar as novas gerações nos conhecimentos necessários à participação na vida social. Esta é, porém, uma definição limitada à função geral formal que historicamente foi difundida como própria da escola, função esta que, em sua configuração formal, explicita pouco sobre a formação social efetivamente realizada pela escola, ocultando aspectos relevantes que vêm constituindo de fato a ação escolar pública ao longo da história, atualizando suas utilidades em diferentes contextos históricos e geográficos.

Alguns dos aspectos ocultados podem ser diretamente relacionados às políticas sociais que, para os fins deste artigo, serão sinteticamente definidas como as políticas públicas que, contemporaneamente, apresentam-se mais diretamente vinculadas à regulação das diferentes formas de acesso aos direitos sociais. Nessa acepção, referenciada em autores como Foucault (2008) e Castel (1998), as políticas sociais podem ser definidas como políticas referidas aos âmbitos da vida social reconhecidos, em cada contexto, como âmbitos de práticas fundamentais à participação na vida coletiva, dentre os quais podemos destacar o da saúde, da assistência, do trabalho, da previdência e, claro, da educação.

O termo políticas sociais (no plural) não se confunde com política social (no singular), que, em nossa compreensão, designa um conjunto mais complexo de políticas, medidas e disposições que incidem sobre as condições de acesso e participação na vida econômica e social. Cabe lembrar, neste caso, os alertas feitos por autores como Francisco de Oliveira (1972) e Wanderley Guilherme dos Santos (1987), quando mostram, por exemplo, que o salário mínimo é algo bem mais complexo que um "direito do trabalhador", constituindo-se como um item, simultaneamente, da política econômica e da política social, item este que incide sobre aspectos fundamentais da vida social, podendo, por si, funcionar tanto como um mecanismo de regulação do acesso ao consumo de bens básicos, quanto como um mecanismo de contenção e ordenamento das forças sociais que participam da disputa dos direitos vinculados ao trabalho em cada contexto, dentre outros aspectos.

Tendo-se isto em conta, deve-se reconhecer a política social como o conjunto constituído não apenas pelas políticas setoriais diretamente inscritas no âmbito das práticas, direitos e regulações sociais, mas também por medidas e ações que, apesar de organizacionalmente se apresentarem como item de outras políticas (econômica, por exemplo), cumprem relevantes funções na regulação da vida social. De todo 
modo, o termo políticas sociais faz referência às políticas setoriais que integram o campo alargado da política social, e que, em geral, configuram-se e se realizam por meio da atuação sistemática do Estado, ancorando-se, em grande parte, no financiamento público.

Pois bem, feitas essas considerações, é forçoso reconhecer que a escola pública, ao longo da história, não pode ser compreendida em suas efetivas funções se não levarmos em conta seus nexos com as diversas políticas sociais e com a política social, em geral. Primeiro, porque as definições das funções da escola não se deram na forma de revelação mágica de uma suposta essência da escola como instituição. Como toda instituição social, a escola, tal como aprendemos com Gramsci (2000a e 2000b), foi produzida historicamente a partir das tensões, choques e combinações entre intencionalidades e demandas distintas. Por isso, o que dela conhecemos é o resultado histórico das correlações de forças atuantes na sua produção, uso e disputa, ao longo de um emaranhado de processos que têm em comum o fato de serem processos também atuantes na produção histórica do Estado, como um todo, e, especialmente, das especializações de funções que garantiriam aos Estados nacionais, a partir do século XIX, certas condições de controle e acompanhamento do território e da população.

Nesse contexto, educação pública, previdência social, saúde pública, assistência social, dentre outras políticas setoriais, foram produzidas e ainda o são por meio de processos complexos em que são convencionadas especificidades, fronteiras setoriais, mas também relações entre os diferentes âmbitos de cada política consolidada e os novos âmbitos de ação política que vão sendo enunciados e instituídos.

E isso se dá de tal modo que, se olharmos para a política social, hoje, no Brasil, veremos que não temos mais como defini-la como uma esfera constituída por políticas setoriais clássicas como saúde, educação e assistência, já que novos setores de ação estatal vêm se constituindo (como o setor de juventude e de idosos), assim como novos eixos de ação multi e intersetorial ${ }^{3}$. Nesse processo, não apenas são abaladas as supostas fronteiras entre as políticas constituídas, mas também são redefinidas suas relações e, por conseguinte, a própria designação do que seria "próprio" de cada política em particular.

A discussão sobre os desafios da escola na relação com as políticas sociais precisa levar isso em conta, ou seja, reconhecer que essa relação é inerente à escola, e que, portanto, para abordá-la, temos que considerar as reconfigurações na política social, no seu conjunto, nas políticas setoriais que a integram e nas suas efetivas inter-relações ao longo da história e no atual contexto.

Por isso, para realizarmos essa discussão, nos limites deste artigo, propomos, como estratégia, começar pela realização de um breve exercício analítico sobre um eixo de ação política que se definiu, historicamente, na inter-relação entre políticas

\footnotetext{
${ }^{3}$ A esse respeito, reportamo-nos especialmente a Almeida, Monnerat e Souza (2014).
} 


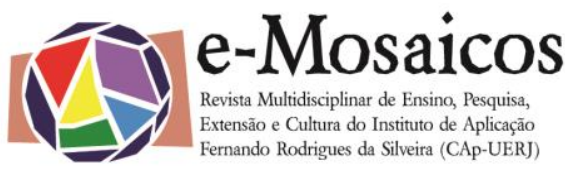

DOI: $10.12957 /$ e-mosaicos.2017.30296

sociais e a escola: a saúde escolar. Tentaremos extrair desse exemplo histórico alguns elementos indicativos de problemas típicos dessas inter-relações cuja consideração pode nos ajudar na análise das relações atuais entre escola pública e políticas sociais, no Brasil, no atual contexto.

\section{PolítICAS SOCIAIS E ESCOLARIZAÇÃO NA PRODUÇÃo DA ESCOLA PÚBLICA NO BRASIL: QUESTÕES A PARTIR DA HISTÓRIA DA SAÚDE ESCOLAR}

A produção da escola pública no Brasil foi e é marcada por inúmeras formas de nexos entre a escolarização da população e a realização ou promessa de realização de políticas sociais distintas, envolvendo relações pontuais ou sistemáticas da política educacional com políticas de saúde, de assistência, de trabalho, de cultura, de lazer e, até mesmo, de habitação popular. Nossa proposta, neste artigo, é realizar uma discussão exploratória da saúde escolar como política na qual a consideração das formas de realização das inter-relações entre escolarização e política de saúde pode nos propiciar referências relevantes para pensarmos as relações entre escolarização e políticas sociais no atual contexto.

Os estudos sobre saúde escolar, como âmbito de atuação sistemática do Estado, costumam situar seus primeiros momentos de constituição na Alemanha, em fins do século XVIII, quando o médico alemão Johann Peter Frank (1745-1821) elaborou uma espécie de tratado de política médica ${ }^{4}$ que abordava, por inúmeros ângulos, as relações entre saúde e doença no contexto das relações sociais. Nesse tratado, em que o autor abordou diversos aspectos da saúde individual e da saúde coletiva $^{5}$, a questão da saúde relacionada aos processos e condições de escolarização foi objeto de detalhadas discussões e proposições que, ainda hoje, referenciam, sob diversos prismas, as formulações e práticas relacionadas ao que então passou a ser referido como "saúde escolar".

Um aspecto a destacar, nas formulações de Frank, diz respeito à percepção da escola como um espaço multiplamente implicado com a questão da saúde: como espaço de convívio coletivo cotidiano, a escola era, inevitavelmente, lugar de incidência de acidentes e de práticas relacionadas à propensão ao adoecimento; e, como instituição educativa, a escola se definia como potencialmente adequada à disseminação de práticas, orientações e disposições capazes de interferir

\footnotetext{
4 Trata-se de uma obra em 9 (nove) volumes, intitulada "System einervollständigenmedicinischenPolizey" (Sistema Completo de Polícia Médica), posteriormente conhecido como Sistema Frank. Observe-se que, no contexto de elaboração do referido Sistema, o termo "polícia" designa mais propriamente uma política sistemática de intervenção e acompanhamento, que envolve funções repressivas, mas não se restringe a elas, não coincidindo, portanto, com o significado predominantemente atribuído ao termo no século $X X$, referente a um setor especializado de ação - a Polícia - e ao corpo profissional a quem cabe coordená-la e executála, cujas funções centrais são eminentemente repressivas.

5 Dentre os aspectos abordados, podem ser destacados, segundo Rosen (1979), "demografia, casamento, procriação, puerpério, saúde infantil, medicina militar, doenças infecto-contagiosas, vestuário, esgotos, suprimento de água e prevenção de acidentes".
} 
positivamente na promoção da saúde e na prevenção e controle de doenças. Daí as disposições detalhadas de Frank sobre diversificados aspectos, como os concernentes à higiene pessoal, física e mental; às questões de salubridade dos espaços de uso coletivo, como iluminação, aquecimento e ventilação das salas; às práticas promotoras de saúde física, como o atletismo; e aos aspectos organizacionais da instituição escolar, como os concernentes ao atendimento escolar e à supervisão.

Como mostra Foucault (2008), não podemos entender as proposições e ações do Estado, em cada contexto histórico e social, se não levamos em conta que os saberes que servem de base a essas ações não são linearmente originários de tratados e doutrinas que antecederiam as práticas estatais concretas, orientando-as em determinados sentidos. Ao contrário, inúmeros dos tratados de políticas resultavam da observação sistemática das práticas reais, de onde eram colhidos os exemplos do que deveria ser banido, evitado, reproduzido, atualizado, intensificado ou generalizado. Além disso, muitas das ações que, observadas retrospectivamente, podem nos parecer regidas por procedimentos previamente normatizados, tal o seu grau de ordenamento lógico e sistematicidade, haviam emergido, na verdade, "no interior mesmo da prática administrativa", como "políticas praticadas", "concebidas sem teoria" e, gradualmente, institucionalizadas por meio de uma multiplicidade de medidas normativas de diferentes tipos e escalas (FOUCAULT, 2008, p. 428).

Assim, cabe esclarecer que não se quer, aqui, imputar as políticas de saúde escolar unicamente às ideias de Johann Peter Frank. Tomamos suas formulações como síntese de orientações que, posteriormente, apareceriam concretamente no delineamento de políticas de saúde escolar em diversos países (e de modo exemplar na Alemanha), entendendo que o tratado por ele produzido, largamente reconhecido como uma sistematização exaustiva das possibilidades de ordenamento e uso das práticas e procedimentos no campo da saúde, constitui-se, a um mesmo tempo, como expressão de questões e práticas postas em seu tempo, e como fundamento central no campo da saúde pública, em geral, e no campo da saúde escolar, em particular, tendo em vista sua sistematicidade e sua intensa difusão.

Pois bem: também por seu modo particularmente sistemático de realização, a experiência de institucionalização da saúde escolar na Alemanha nos propicia indicações relevantes para a compreensão das motivações e impasses implicados nas inter-relações entre a escolarização e outras políticas sociais. Estudos nesse campo, como os de Lima (1985) e os de Ferrani (1991), permitem-nos perceber, por exemplo, que os serviços públicos de saúde, naquele contexto, foram vinculados à escola por, pelo menos, cinco principais motivos.

Em primeiro lugar, porque a escola dava visibilidade a questões de saúde individual e coletiva que não eram suficientemente perceptíveis em outros âmbitos de convívio e prática social: limitações visuais, auditivas, de fala e intelectuais, por exemplo, tornavam-se mais visíveis na escola, assim como características comportamentais que podiam ser reputadas à família ou a certas comunidades. 


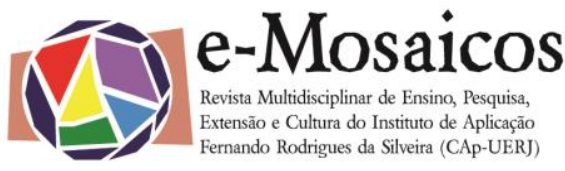

DOI: $10.12957 /$ e-mosaicos.2017.30296

Em segundo lugar, porque, por ser um espaço de uso coletivo cotidiano e de prolongado convívio, a escola era um lugar propício à disseminação de doenças. A proximidade e o contato físico direto, bem como o manuseio e uso comum de objetos e utensílios, favoreciam o contágio de doenças diversas e a transmissão de parasitas, como piolhos e sarna. Parte da noção de saúde pública se desenvolve a partir dessa situação particular: os espaços públicos, por implicarem, em geral, uso coletivo, estão sujeitos a riscos inerentes ao caráter coletivo de seu uso, requerendo seu ajuste a regras de convívio, de salubridade, etc.

Em terceiro lugar, porque, tal como já discutimos em trabalhos anteriores (ALGEBAILE, 2009 e 2013), ao se organizar, já no século XIX, segundo uma expectativa de largo alcance populacional, a escola foi se constituindo como um equipamento público tendente a um padrão de difusão territorial que propiciava, ao Estado nacional em consolidação, certas condições de presença no território que lhe eram extremamente úteis, ensejando-lhe novas possibilidades de organizar parte de suas ações.A disseminação de estabelecimentos interligados administrativamente na forma de redes favorecia sua utilização como base de ações estatais sistemáticas, padronizadas e regulares. Por sua vez, assim organizadas, tais ações podiam ser inter-relacionadas a outras redes de ações. Por exemplo, a regularidade, sistematicidade e padronização das ações escolares possibilitavam a notação de ocorrências e o registro de informações úteis para a alimentação de bases estatísticas sobre a escola, mas também sobre o escolar, sua família, suas condições de vida e, por conseguinte, sobre demografia, economia e território.

Se considerarmos que a constituição dos sistemas nacionais de ensino na Europa foi significativamente marcada pela difusão de redes de estabelecimentos escolares com estruturas físicas e organizacionais pouco discrepantes, fica evidente que a gradual solidez e regularidade das redes escolares suscitou a possibilidade de ações que, hoje, poderíamos chamar de "multisetoriais" ou "intersetoriais" inevitavelmente influiu no delineamento da escola e das políticas que por sua via adquiriam novas condições de realização.

Um quarto motivo é que o padrão de funcionamento da escola como instituição (um funcionamento cotidiano e, portanto, implicado com relações intraescolares de duração diária prolongada e com relações extraescolares regulares, como no caso do contato com as famílias e demais instituições locais) favorecia um tipo de proximidade dos eventos vinculados à relação saúde-doença que, por si, garantia uma condição ótima de monitoramento, prevenção e intervenção nas possibilidades de ocorrência de doenças.

\footnotetext{
${ }^{6} \mathrm{O}$ termo multisetorialidade designaria, neste caso, principalmente, as ações com responsabilidades e execução subdivididas de forma cooperativa, ou ao menos relativamente compartilhadas, entre vários setores de políticas. Em sentido diverso, o termo intersetorialidade designaria um princípio, lógica e estratégia (PEREIRA, 2014) de "construção de interfaces entre setores e instituições governamentais (e não governamentais), visando o enfrentamento de problemas sociais complexos que ultrapassem a alçada de um só setor de governo ou área de política pública", pressupondo "o imperativo da integração entre as políticas" (MONNERAT e SOUZA, 2011, p. 41).
} 


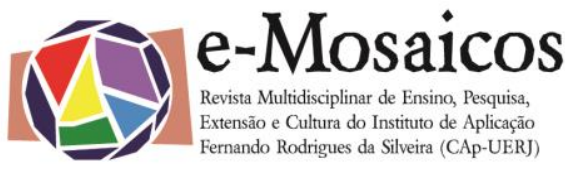

DOI: $10.12957 /$ e-mosaicos.2017.30296

E um quinto motivo é que, ao avançar decisivamente em direção à universalização de seu alcance, o sistema escolar facultou, ao setor de saúde, condições especiais para sua própria universalização, já que, como mostra Lima (1985), as "crianças em idade escolar" (que naquele momento histórico, na Alemanha, eram as crianças na faixa etária dos 7 aos 11 ou 12 anos) eram um segmento populacional cujas características biológicas correlacionavam-se a formas e possibilidades de adoecimento mais facilmente acompanháveis por meio de uma instituição cujo funcionamento implicava a frequência cotidiana.

Essa breve incursão na história da saúde escolar, ainda que realmente muito breve, permite-nos observar certos aspectos da lógica de realização de serviços de saúde via escola no Brasil que, acreditamos, são indicativos de problemas similares nas relações entre a escola e as demais políticas sociais.

Um primeiro aspecto a destacar é que, no contexto brasileiro, as ideias de saúde escolar chegam em um momento no qual as escolas não só não estavam bem distribuídas territorialmente, como sua difusão pelo território se dava segundo um padrão de crescente e dinâmica diferenciação dos próprios padrões de escola e de escolarização. Os equipamentos escolares e os processos de escolarização se constituíam, portanto, como bases estruturalmente desiguais para "portarem" as novas tarefas.

Outro aspecto a destacar é que, em nosso contexto, mesmo no início do século $\mathrm{XX}$, quando as proposições de saúde escolar ganharam força, os demais serviços públicos apresentavam debilidades ainda maiores que as observadas na organização das redes de escolas, e isto em termos de seu alcance populacional e de sua difusão territorial. Assim, os "pacotes" de ações remetidos às escolas não apenas se disseminavam em uma rede falha e desigual. Eram, eles próprios, também desiguais, inclusive em sua regularidade.

Além disso, como adequadamente insiste Lima (1985), não podemos esquecer que a maioria das crianças em idade escolar não estava na escola. Assim, a migração de tarefas de saúde para a escola não representava efetivamente maior alcance das ações de saúde, mas sua contenção nos limites do alcance populacional e territorial da escola.

Uma das expressões disto é o caráter residual ou pouco estruturado dos serviços de saúde realizados via escola. A escola pública no Brasil foi e é palco de inúmeras ações do campo da saúde cuja realização não contou com nenhuma modificação ou com modificações suficientes dos estabelecimentos escolares que os tornassem espaços capazes de realizar tais ações com regularidade e segundo um mesmo padrão. Não raras vezes, também é possível observar que parte das supostas ações de "saúde via escola" não apresenta padrão minimamente próximo às suas formas de realização em instituições de saúde pública bem estruturadas. Assim, ainda que a história da saúde escolar no Brasil seja constituída por experiências locais (especialmente em capitais de estado e em grandes e médias cidades) expressivas de significativa estruturação, tais experiências não representam um 


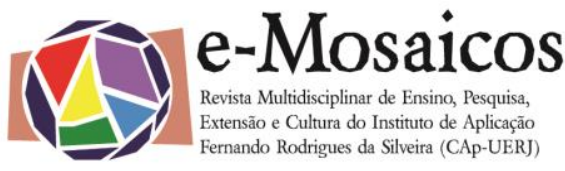

DOI: $10.12957 /$ e-mosaicos.2017.30296

padrão disseminado em território nacional, constituindo o quadro brasileiro como variações que não suplantaram a forte presença da experimentação, da irregularidade, da insuficiência, da inadequação e outras mazelas na constituição do quadro geral real de realização de ações de saúde via escola.

Outro problema a observar diz respeito à tendência à utilização sistemática (e não pontual)da infraestrutura escolar para a realização das tarefas concebidas como constitutivas do campo da saúde escolar. Os aspectos implicados nessa questão são variados. Por exemplo, se é verdade que em diversas cidades, ou mesmo em parte dos estados, as políticas de saúde escolar envolveram, em diferentes momentos, a instalação de gabinetes dentários ou pequenos postos de atendimento médico, é igualmente verdade que, em muitos casos, a manutenção de parte dessa infraestrutura onerava de diversas formas o setor educacional, seja por ser custeada obscuramente por recursos financeiros vinculados orçamentariamente à manutenção e desenvolvimento do ensino, seja pela multiplicação de problemas de gestão escolar relacionados à degradação e desmonte de parte da infraestrutura produzida, seja, ainda, pelo deslocamento de profissionais do campo escolar para a realização de tarefas burocráticas que davam suporte às ações de saúde, dentre outros aspectos. A sobre utilização do espaço, do tempo e dos recursos da escola, sem a devida contrapartida, na forma de recursos financeiros, materiais e institucionais adicionais, é, sem dúvida, um dos fatores de contenção ou degradação das condições básicas necessárias à plena manutenção e desenvolvimento do ensino, provocando tensões e desgastes que influem também subjetivamente sobre o campo educativo escolar.

Mais um problema pode ser reconhecido na tendência à subordinação das tarefas educativas aos propósitos dos programas e ações da área de saúde e, mesmo, à secundarização da educação escolar, em sentido amplo, frente às atividades "formativas" da área de saúde.

A experiência histórica da saúde escolar mostra que a escola pública destinada aos segmentos populares foi sistematicamente vista e usada como um meio instrumental (e redutor) de "formação para a saúde" que desresponsabilizava o Estado em relação à garantia das condições gerais de vida e se sobrepunha à formação geral que deveria ser o centro da formação pública escolar. Com o argumento de que a escola era importante para a difusão de instruções relativas à higiene e ao desenvolvimento de comportamentos e práticas constitutivos de cuidados preventivos com a saúde, proliferaram programas e ações de formação para a saúde que, como bem mostrou Valla (1986) em seus estudos, pareciam desconhecer a inexistência de condições concretas para sua consolidação. Crianças cujas habitações não eram regularmente abastecidas de água e não dispunham de instalações sanitárias minimamente estruturadas eram (e ainda são!) ensinadas a lavar as mãos antes das refeições e após o uso do sanitário. Instruções sobre a alimentação sadia eram passadas em contextos nos quais sequer se tinha a garantia de fazer uma refeição completa por dia. Note-se que, nesse quadro, inúmeras práticas formativas vinculadas à saúde escolar realizavam a função principal de transmutar as ausências do Estado em problemas de educação do povo: o Estado 
isentava-se de produzir as condições concretas (de saúde pública, saneamento, habitação, trabalho etc.) que constituem as bases reais do desenvolvimento e consolidação de saberes e comportamentos necessários à saúde, deixando a cargo da ação escolar tarefas de "formar para a saúde" que passavam a concorrer com os demais conhecimentos cuja relação sistemática só poderia ter lugar na escola.

Um dos efeitos desse conjunto de problemas é a tendência ao estabelecimento de relações tensas, concorrentes e conflituosas entre os diferentes setores de políticas, seus profissionais e os sujeitos do direito à educação. A saúde escolar, com frequência, representou a consolidação de uma posição de autoridade do médico e do psicólogo sobre a educação, dando base a um maior poder de disposição do campo médico sobre o professor, os alunos e suas famílias. As questões implicadas no quadro e na dinâmica de relações constituídos segundo essa lógica são muitas, envolvendo inclusive a tendência à medicalização do fracasso escolar. Neste artigo, porém, gostaríamos de destacar o quanto esse quadro é desagregador, contribuindo para a progressiva erosão das relações escolares, em geral, para a erosão da situação profissional (em sentido ampliado) do professor, e para a desqualificação dos alunos e de suas famílias para disporem sobre as ações a eles dirigidas.

Voltaremos a este ponto adiante. Por hora, é suficiente lembrar que esses problemas, em suas linhas gerais, podem ser tomados como referência para pensarmos, ainda que de forma exploratória, os impasses contemporâneos com a realização de tarefas de outras políticas setoriais via escola. E o caso das ações do campo da assistência social é, aqui, particularmente importante, tendo em vista ser o campo cuja relação com o setor educacional e a escola está se dando com intensidade equivalente à das relações com a saúde até duas décadas atrás.

\section{DESLOCANDO O FOCO DE OBSERVAÇÃO: EsColarizaÇÃo E ASSISTÊNCIA SOCIAL NO BRASIL ONTEM E HOJE}

Ao correlacionarmos a experiência histórica de relação entre saúde e escola pública com a experiência histórica e contemporânea de relação entre escola e assistência social, muitas questões instigantes sobressaem.

Preliminarmente, é importante lembrar que, assim como a saúde pública, a assistência social também se mostra presente na constituição do âmbito ampliado da "ação escolar" desde os primórdios da escola de massa no Brasil. Mas é imperativo identificar que o ingresso massivo de diferentes frações da classe trabalhadora na escola, especialmente os segmentos populacionais mais pauperizados, somado ao contexto de mudanças econômicas, políticas e sociais implicado com a reconfiguração do Estado e da política social, nas três últimas décadas, reacende, intensifica ou reconfigura vários dos aspectos observados na história da saúde escolar: 


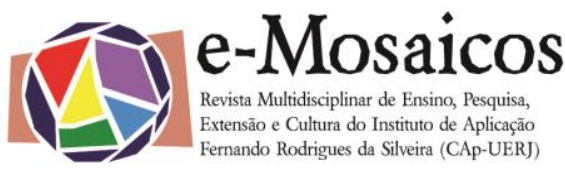

DOI: $10.12957 /$ e-mosaicos.2017.30296

Se nas décadas 1950 e 1960, quando a saúde escolar mostrava-se em franca expansão, as ações do campo da assistência social eram esparsas e pontuais, fora ou dentro da escola, onerando pouco ou nada as bases e os recursos educacionais, o panorama encontrado a partir da década de 1990 é bastante diverso, evidenciando um intenso uso estratégico da infraestrutura e da ação escolar para a realização da assistência, a partir de então em franca expansão.

Há, porém, particularidades relevantes nessas formas de uso, quando comparadas às formas que predominavam na realização da saúde escolar. Por exemplo, hoje, por um lado, as redes de escolas mostram-se significativamente disseminadas em território nacional, indicando, em tese, que a realização de diferentes políticas via escola tende a garantir uma adequada expansão da sua cobertura populacional. Essas redes de escolas, porém, ainda são fortemente marcadas por impressionantes diferenças materiais e institucionais, de forma que os equipamentos escolares e os processos de escolarização se mantêm, em boa parte, como bases estruturalmente desiguais para "portarem" as novas tarefas vinculadas à assistência.

A esse respeito, há diferenças de encaminhamento das políticas e programas sociais vinculados à escolarização que não podem ser ignoradas. 0 padrão de utilização da infraestrutura e dos recursos educacionais para a realização de ações do campo social apresenta significativas diferenças, por exemplo, quando se compara a atuação do governo federal nas gestões de Fernando Henrique Cardoso e nas gestões de Luiz Inácio Lula da Silva ${ }^{7}$. Se no primeiro predomina largamente a realização de programas sociais a partir das bases e dos recursos educacionais, no segundo são gradualmente elaboradas políticas (especialmente expressas na Política Nacional de Assistência Social) que a médio e longo prazos tendem a propiciar a constituição de uma malha institucional capaz de conferir tanto bases e recursos próprios ao campo ampliado da assistência social, quanto a extensão de bases para a realização de ações de campos variados, como de saúde e educação, na perspectiva da intersetorialidade. Mas como tal malha não se encontra consolidada, e como, nesse segundo período, os programas sociais multiplicam-se e expandem em muito sua escala de realização, as condições gerais de realização das relações entre serviço

\footnotetext{
${ }^{7}$ Não é possível fazer, nos limites deste trabalho, uma análise, ainda que breve, do perfil assumido pela política social nessas diferentes gestões, tendo em vista a multiplicidade de aspectos que deveriam ser considerados para se ter um panorama minimamente expressivo dos quadros de concepção e ação delineados nos dois contextos. Por exemplo, para além da ação diretamente estatal, que já envolve uma enormidade de aspectos, tal análise deveria considerar também as formas diversas de incorporação de organizações sociais para a realização de ações no campo social, as questões relativas ao financiamento público relacionado a terceirizações, dentre outros problemas. Assim, partindo do reconhecimento dessas limitações, as indicações acima tentam apenas sinalizara necessidade de atenção às diferenças no que diz respeito a certos aspectos de organização da política de assistência social e, no seu interior, aos delineamentos e ao lugar central atribuídos aos programas sociais de variados recortes, com ênfase nos programas sociais vinculados à escolarização, tendo em vista que, independentemente de sua boa ou má avaliação, tais diferenças estão implicadas com a constituição de condições objetivas e subjetivas distintas que precisam ser levadas em conta na análise dos desafios da escola pública na relação com as políticas sociais.
} 


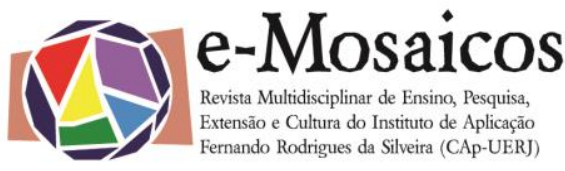

DOI: $10.12957 /$ e-mosaicos.2017.30296

social e escolarização reiteram ou criam novos impasses de difícil compreensão, como, em especial, os relacionados à grande diversificação da ação estatal nesse campo ampliado.

É importante lembrar que, no mesmo contexto (pelo menos as últimas três décadas), a assistência social (como política)e o serviço social (como campo profissional) vêm sendo reconfigurados. Não podemos, nos limites deste artigo, expor extensivamente os diferentes aspectos dessa reconfiguração. Mas a consideração de três aspectos que nos parecem centrais talvez nos dê um ponto de partida razoável para a discussão em curso.

O primeiro aspecto a considerar é que não podemos ignorar que, nessas últimas três décadas, o campo da assistência social passou por relevantes mudanças em termos da produção de conhecimento crítico sobre as relações econômicas, sociais e políticas no contexto capitalista, destacando-se as questões concernentes ao Estado e suas ações em face das desigualdades produzidas nesse contexto. Tal conhecimento, fundado em compromissos com as lutas por transformações sociais, tem tido, desde então, uma impressionante influência sobre a formação de profissionais do campo social e sobre a elaboração e o debate de políticas públicas. A forma de definição de direitos sociais na Constituição Federal de 1988 e alguns de seus importantes desdobramentos trazem a marca desses conhecimentos e desses compromissos, alterando concreta e potencialmente a forma de presença dos profissionais do serviço social nos espaços de discussão, formulação e execução de políticas sociais.

O segundo aspecto, porém, é relativo às tensões e perdas relacionadas ao modo concreto como a ação do Estado no campo social passa a se organizar hegemonicamente no mesmo período. É importante destacar, neste caso, na recomposição da política de assistência social e de outras políticas setoriais, como trabalho, educação e saúde, a partir da década de 1990, a presença central de uma multiplicidade de programas e ações focais dirigidos a diferentes segmentos da população e a diferentes demarcações territoriais. Entendemos que a análise dos programas, medidas e ações implicados, hoje, com a política social reconfigurada, requer que sejamos cuidadosos, evitando generalizações que apaguem as movimentações contraditórias que também constituem os processos de realização de cada programa e de suas inter-relações. Porém, é igualmente necessário reconhecer que os efeitos de diversos programas, isoladamente, bem como os efeitos de conjunto dessa multiplicidade de programas têm, por si, problemas que não podem ser desprezados.

O terceiro aspecto é, pois, relativo à situação de atuação profissional do serviço social configurada pela confluência dos dois aspectos acima apresentados, ou seja, a situação na qual o serviço social tem sido acionado de formas muito diversificadas para a realização de tarefas relacionadas a essa multiplicidade de programas, aparecendo ora como campo profissional executor, ora como 
coordenador de programas específicos, ora, ainda como coordenador dos campos intersetoriais de ação que estão se constituindo nesse contexto.

Pois bem: é relacionada a esse quadro (ainda que não somente a ele) que aesfera e a ação escolar (e, no seu interior, a formação escolar e a assistência via escola) entram em uma nova e mais intensa fase de modificações. A intensificação da realização a um mesmo tempo massiva e multifacetada da assistência social via escola produz alterações fundamentais na assistência e na educação escolar e, por consequência, na definição das formas de atuação profissional dos dois setores.Mas como os profissionais do serviço social trazem as marcas de uma formação crítica extremamente potente, essas alterações são constituídas, simultaneamente, por potencialidades contraditórias.

De um lado, a chegada de profissionais do serviço social na escola se dá, em vários casos, na forma de chegada de um profissional disposto a indagar construtivamente sobre as naturalizações das desigualdades que se multiplicam no próprio seio da educação escolar; a apartação entre profissionais, alunos e pais de alunos; a cultura autoritária e conservadora que, sabemos, marca de forma dura a história da educação escolar no Brasil. Essas indagações, inúmeras vezes, ecoam de forma motivadora dentro do setor educacional e da escola, reforçando os acúmulos críticos e os compromissos que também ali, há muito, vêm se construindo, nas tentativas de formação e trabalho coletivo, nas tarefas de construção do movimento sindical, nos embates da categoria docente e das associações de pais e alunos em relação à escola pública, ao trabalho escolar e ao direito pleno à educação. Ao mesmo tempo, porém, dependendo da sua forma de concepção, gestão e realização, o serviço social via escola pode manter presente a tendência à subordinação das tarefas educativas (em sentido estrito) aos propósitos dos programas e ações, dos diversos níveis governamentais, que passam a compor a esfera ampliada da escolarização. Um risco vinculado a esse é a reedição de posições de autoridade das equipes profissionais do campo do serviço social sobre a educação, a escola, o professor, em detrimento das relações horizontais de colaboração, troca e compromisso que são as necessárias na reconstrução das políticas referidas a direitos.

De outro lado, no entanto, a lógica anteriormente indicada, segundo a qual está se dando a intensificação da assistência social via escola, implicasobrecarga de tarefas atribuídas aos profissionais da educação e aos profissionais do serviço social e do campo ampliado de ação por ele nucleado. Tal sobrecarga não resulta apenas da quantidade de tarefas, mas também (e fortemente) da diversificação e instabilidade das ações. O fracionamento de programas e de procedimentos a eles associados lança esses profissionais em agendas sobrepostas, em intensos deslocamentos entre estabelecimentos, na participação intermitente em variados programas de formação continuada, dentre outras atividades e situações que, em conjunto, drenam cotidianamente esforços e dispersam atenção, reduzindo tendencialmente as possibilidades desses profissionais elaborarem colaborativamente 
análises críticas e estratégias capazes de darem base e dinâmica à disputa coletiva dos sentidos das ações realizadas.

Trabalha-se muito, mas como se cada um realizasse o atendimento de sucessivos problemas em um balcão. Não há o distanciamento e o tempo que seriam necessários para, ao longo ou ao final do dia, da semana, do mês, organizar coletivamente acúmulos sobre o processo de trabalho que permitam desvendar seus ardis, propor formas de superá-los, organizar ações e intervenções capazes de incidir efetivamente sobre a forma de definição e realização da política na qual se atua. 0 próprio conteúdo das tarefas prescritas para as duas esferas profissionais aí implicadas as coloca, muitas vezes, em relações tensas e concorrenciais, alimentando, como indicado acima, confrontos de autoridade. Um dos riscos aqui latentes é o da reconfiguração da "ação escolar" não pela via anunciada de intersetorialidade, mas pela via de uma multisetorialidadeque reforça a relação concorrencial entre os setores escolar e de assistência.

\section{CONSIDERAÇÕES FINAIS}

O que foi discutido até aqui nos permite sintetizar uma breve pauta do que podemos considerar como desafios centrais para a escola pública na relação com as políticas sociais.

Primeiramente, entendemos ser fundamental afirmar que, no atual contexto, a presença de políticas sociais na escola ou realizadas em relação com a escola não pode ser recusada. O maior alcance populacional da escola no Brasil implicou o ingresso de segmentos sociais historicamente alijados de direitos, e a construção de novas bases para o exercício efetivo desses direitos passa, dentre outras medidas, pela superação de um padrão de ação estatal definido por uma setorialização que segmenta a relação do Estado com os problemas da vida econômica e social, dispersando energias e recursos e dificultando o enfrentamento das desigualdades instaladas no próprio interior de cada serviço referido a direitos. Querer uma "escola pura", apartada das demais políticas sociais, é negar a esses segmentos a possibilidade de ampliar suas relações e seu acesso a vias que, direta ou indiretamente, podem ampliar sua proximidade (e, por conseguinte, sua capacidade de luta e disputa) com a questão dos direitos.

Em segundo lugar, porém, parece também estar claro que as relações entre a escola pública e as demais políticas sociais:

a) não devem ser construídas de forma parasitária sobre os recursos e as energias da escola;

b) não podem provocar seu transformismo em registro negativo, ou seja, subalternizando as funções e tarefas de relação com o conhecimento que cabem centralmente à escola; 
c) não devem implicar o sequestro do trabalho do professor para tarefas administrativas, de controle etc., nem o agenciamento do trabalho do serviço social a favor de propósitos que ferem, em profundidade, a compreensão sobre direitos sociais que faz desse campo de conhecimento e formação, hoje, um dos campos de melhor elaboração crítica sobre o tema;

d) e não podem provocar e mesmo permitir a apartação e a relação concorrencial entre profissionais dos diversos setores e entre estes e os sujeitos de direitos.

Para estar a serviço dos sujeitos de direitos e não das necessidades instrumentais de recomposição do Estado, a relação entre a escola pública e as políticas sociais deve se ancorar em proposições e práticas discutidas, elaboradas e conduzidas horizontalmente pelos profissionais dos setores atuantes na produção cotidiana da escola e pelos sujeitos de direitos da escola.

Ninguém ganha com uma escola em que os professores e os alunos não são nada. Também não há ganhos legítimos, em termos políticos, sociais e humanos, com a inserção de profissionais do campo do serviço social na esfera escolar ampliada se esses profissionais são previamente inseridos em posições de concorrência com os demais profissionais; se são previamente tratados pela administração pública como interventores; se são tratados, tal como se faz historicamente com os professores, como executores subalternos de uma política traçada a partir de uma perspectiva que fere os avanços de sua formação.

Isto deve nos levar a refletir sobre os efeitos intencionais e sobre as derivas de políticas e ações que se mostram especialmente potentes em termos do ajuste, do controle e da subordinação dos sujeitos - alunos, profissionais, famílias - que deveriam ter posição central na produção da escola e da política social.

Nesse sentido, a intensificação contemporânea das relações sistemáticas entre a escola pública e o serviço social pode e deve ser tomada como uma possibilidade de construção de solidariedades e compromissos, entre profissionais e sujeitos de direitos, absolutamente necessários para se disputar os sentidos e os projetos de educação e de escola em uma perspectiva efetivamente pública.

\section{REFERÊNCIAS BIBLIOGRÁFICAS}

ALGEBAILE, E. Escola pública e pobreza no Brasil: a ampliação para menos. Rio de Janeiro: Lamparina/Faperj, 2009.

A expansão escolar em reconfiguração. Revista Contemporânea de Educação, v. 8, p. 198-216, 2013. Disponível em: http://www.revistacontemporanea.fe.ufrj.br/index.php/contemporanea/article/view/3 $74 / 212$

ALMEIDA, N. L. T. de (Org.); MONNERAT, G. (Org.); SOUZA, R. G. (Org.). $A$ intersetorialidade na agenda das políticas sociais. São Paulo: Papel Social, 2014. 
CASTEL, R.. As metamorfoses da questão social: uma crônica do salário. Petrópolis: Vozes, 1998.

FOUCAULT, M. Segurança, território e população. São Paulo: Martins Fontes, 2008.

GRAMSCI, A. Cadernos do cárcere. Volume 2. Os intelectuais. O princípio educativo. Jornalismo. Rio de Janeiro: Civilização Brasileira, 2000a.

Cadernos do cárcere. Volume 3. Maquiavel. Notas sobre o Estado e a política. Rio de Janeiro: Civilização Brasileira, 2000b.

LIMA, G. Z.de. Saúde escolar e educação. São Paulo: Cortez, 1985.

MONNERAT, G. L.; SOUZA, R. G. de. Da Seguridade Social à intersetorialidade: reflexões sobre a integração das políticas sociais no Brasil. Revista Katálysis (Impresso), Florianópolis, v. 14, n. 1, p. 41-49, jan./jun. 2011.

OLIVEIRA, F. de. A economia brasileira. Crítica à razão dualista. In: Estudos Cebrap, v. 2. São Paulo: Cebrap, 1972.

PEREIRA, P. A.P. A intersetorialidade das políticas sociais na perspectiva dialética. In: ALMEIDA, N. L. T. de; MONNERAT, G.; SOUZA, R. G. (Orgs.) . A intersetorialidade na agenda das políticas sociais. 1. ed. São Paulo: Papel Social, p. 21-40, 2014.

ROSEN, G.. Da polícia médica à medicina social: ensaios sobre a história da assistência médica. Rio de Janeiro: Edições Graal, 1979.

SANTOS, W. G.. Cidadania e justiça: a política social na ordem brasileira. Rio de Janeiro: Campus, 1987.

VALLA, V. V. (Org.) Educação e favela. Petrópolis: Vozes, 1986. 